\title{
Commentary on: An exploration of sensory and movement differences from the perspective of individuals with autism
}

\author{
Elizabeth B. Torres* \\ Psychology, Computer Science, Cognitive Science, Sensory Motor Integration, Rutgers University, New Brunswick, NJ, USA
}

Keywords: autism, sensorimotor control, sensorimotor integration, self advocates, parents

\section{A commentary on}

An exploration of sensory and movement differences from the perspective of individuals with autism

by Robledo, J., Donnellan, A. M., and Strandt-Conroy, K. Front. Integr. Neurosci. 6:107. doi: 10.3389/fnint.2012.00107

\section{OPEN ACCESS}

Edited by:

Sidney A. Simon,

Duke University, USA

Reviewed by:

Christopher Kliewer,

University of Northern lowa, USA

${ }^{*}$ Correspondence:

Elizabeth B. Torres,

ebtorres@rci.rutgers.edu

Received: 04 February 2015

Paper pending published:

01 March 2015

Accepted: 04 March 2015

Published: 20 March 2015

Citation:

Torres EB (2015) Commentary on: An exploration of sensory and movement

differences from the perspective of individuals with autism.

Front. Integr. Neurosci. 9:20. doi: 10.3389/fnint.2015.00020
"An exploration of sensory and movement differences from the perspective of individuals with autism" by Robledo, Donnellan, and Strandt-Conroy, was originally published in Autism: The Movement Perspective as part of a Research Topic in Frontiers in Integrated Neuroscience (20122014). It gained a special place in the Topic, as in the general field of research in autism, by being one of the few studies to systematically study autism from the perspective of those with that lived experience. This paucity is all the more remarkable as there are at least 100,000 research studies published on the topic of autism in the past few decades (Robertson, 2010). It's hard not to argue that the perspective of autistic people themselves has been given too little attention by the research community although, fortunately, there are a growing number of self-accounts that have helped to shed light on that perspective over the last 25 years adding immensely to our understanding (e.g., Grandin, 1995; Williams, 1998; Mukhopadhyay, 2000).

Nonetheless, this paper by Robledo, Donnellan, and Strandt-Conroy occupies a unique position having called upon multiple rigorous social science research methodologies to study in-depth the presence and potential impact of "movement differences" in autism. They define movement differences as a difference, interference or shift in the efficient, effective utilization, and integration of movement; a disruption in the organization and regulation of perception, action, posture, language, speech, thought, emotion, and/or memory (Leary et al., 1999) which broadens and extends the notions of sensory-motor challenges which have drawn some attention from researchers in recent times (e.g., DSM-5). Using interviews, some in person and some with specialized accommodations for the individual, questionnaires and participant-produced data they present us with revealing and often poignant insights into what has often been defined in social terms as "inappropriate behavior." So Barbara, who has difficulty processing two senses at once chooses to turn her head to limit the visual input and is blamed for this accommodation. This research is an important step beyond the many thousands of studies in the canon showing what autistic people fail to do, or do wrong and little about how they attempt to accommodate to their movement challenges.

The editors of Frontiers and, in particular, the Special Research Issue Autism: The Movement Perspective, were proud to present the 40 papers in that issue, many on topics which do not generally get wide attention. We are particularly proud of this paper that has earned the opportunity to receive even broader readership in a Tier 2 publication. 


\section{References}

Grandin, T. (1995). Thinking in Pictures and Other Reports from my Life with Autism. New York, NY: Doubleday.

Leary, M. R., Hill, D., and Donnellan, (1999). Autism: Myths and Misunderstandings. Ann Arbor, MI: Presented to the School of Psychology, University of Michigan.

Mukhopadhyay, T. R. (2000). Beyond the Silence. London: National Autistic Society.

Robertson, S. (2010). Neurodiversity, quality of life, and autistic adults: shifting research and professional focuses onto real life challenges. J. Learn. Disabil. 26, 545-555. Available online at: http://dsq-sds.org/article/view/1069/1234
Williams, D. (1998). Autism and Sensing: The Unlost Instinct. London: Jessica Kingsley.

Conflict of Interest Statement: The author declares that the research was conducted in the absence of any commercial or financial relationships that could be construed as a potential conflict of interest.

Copyright (C) 2015 Torres. This is an open-access article distributed under the terms of the Creative Commons Attribution License (CC BY). The use, distribution or reproduction in other forums is permitted, provided the original author(s) or licensor are credited and that the original publication in this journal is cited, in accordance with accepted academic practice. No use, distribution or reproduction is permitted which does not comply with these terms. 